\title{
Fixed-combination treatments for intraocular hypertension in Chinese patients - focus on bimatoprost-timolol
}

This article was published in the following Dove Press journal:

Drug Design, Development and Therapy

13 May 2015

Number of times this article has been viewed

\author{
Yuan Fangl,* \\ Zhihong Lingl,* \\ Xinghuai Sun ${ }^{1-4}$ \\ 'Department of Ophthalmology \\ and Visual Science, Eye, Ear, Nose \\ and Throat Hospital, Shanghai Medical \\ College, Fudan University, ${ }^{2}$ Shanghai \\ Key Laboratory of Visual Impairment \\ and Restoration, ${ }^{3}$ Key Laboratory of \\ Myopia, Ministry of Health, ${ }^{4}$ State Key \\ Laboratory of Medical Neurobiology, \\ Institutes of Brain Science, Fudan \\ University, Shanghai, People's \\ Republic of China \\ *These authors contributed equally \\ to this work
}

\begin{abstract}
Glaucoma is a common eye disease that can lead to irreversible vision loss if left untreated. The early diagnosis and treatment of primary open-angle glaucoma is challenging, and visual impairment in Chinese glaucoma patients is a serious concern. Most of these patients need more than one topical antiglaucoma agent to control their intraocular pressures (IOPs). In the People's Republic of China, the daily cost of different glaucoma medication varies greatly, and the treatment habits differ throughout the country. Prostaglandin analogs (PGAs) are recommended as first-line monotherapy, because of their efficacy and low risk of systemic side effects. Fixed-combination drops, particularly PGA-based fixed combinations, have recently been developed and used in patients with progression or who have failed to achieve their target IOPs. Here, we reviewed the current literature on the use of bimatoprost-timolol fixed combination (BTFC) in the People's Republic of China. BTFC has achieved good efficacy and tolerability in Chinese clinical trials. In addition, BTFC is more cost effective compared with other fixed combinations available in the People's Republic of China. Fixed-combination drops may offer benefits, such as keeping the ocular surface healthy, convenience of administration, and improvement in long-term adherence and quality of life. Therefore, BTFC has great potential for the treatment of Chinese glaucoma patients. However, the long-term efficacy of BTFC, comparisons of BTFC with other fixed-combination drugs, and treatment adherence and persistence with treatment in Chinese patients are unknown and will require further study.
\end{abstract}

Keywords: glaucoma, open-angle, bimatoprost

\section{Outline of Chinese glaucoma patients and the management issues with antiglaucoma drops}

Glaucoma is a chronic, progressive disease in which retinal ganglion cells disappear, with a subsequent gradual reduction in the visual field. A glaucoma-related, populationbased study in Asia showed a higher prevalence of glaucoma in Asian patients, including a higher incidence of primary angle-closure glaucoma than in Caucasian patients, with primary open angle glaucoma (POAG) being the most commonly reported. ${ }^{1}$ As reported, the prevalence of glaucoma in the People's Republic of China is approximately $1.95 \%-3.60 \%{ }^{2}$ The prevalence of POAG is $0.86 \%-2.85 \%$ in adults aged 50 years and older living in different places in the People's Republic of China, ${ }^{3-7}$ and this is expected to rise substantially in the coming years as the population ages and the prevalence of myopia increases. There are an estimated 15 million glaucoma patients in the People's Republic of China, including three million who are blind in one eye and 1.2 million who are blind in both eyes. The medical expense of treating glaucoma in the People's Republic of China is about 4.8 billion USD annually; accordingly, the prevention and 
treatment of glaucoma has become an important public health issue in the People's Republic of China. ${ }^{8}$

The goal of glaucoma treatment is to reduce or prevent the loss of visual function and, thus, preserve quality of life. Lowering intraocular pressure (IOP) is currently the only therapeutic approach that preserves visual function. ${ }^{9-14}$

Due to the uneven economic and medical care conditions in the People's Republic of China, POAG is often diagnosed at late stage. A previous Chinese survey showed that at diagnosis, $75 \%$ of patients already had severely damaged visual function with mid- or late-stage glaucoma in at least one eye. ${ }^{15}$ The result of Beijing Eye Study conducted in 2001 revealed that in patients found to have POAG, this was a new diagnosis in $92.30 \%$ of these patients who were from rural areas and in $87.30 \%$ from urban areas. ${ }^{16}$ Patients with newly discovered POAG had severely impaired visual function, and approximately one-fourth of these POAG patients $(26.92 \%$ in rural and $23.64 \%$ in urban) had at least one eye with corrected visual acuity $\leq 0.3$ (low visual acuity, according to the World Health Organization classification). The percentage of POAG patients with monocular blindness was $15.40 \%$ and $10.90 \%$ in rural and urban areas, respectively. ${ }^{16}$ Because of the late diagnosis, these patients need a substantial reduction in IOP to reach their target IOP. In 2007, we performed a cross-sectional survey on the treatment adherence of the antiglaucoma drops to treat Chinese patients at nine hospitals in Beijing and Shanghai and found that $35 \%$ (70/202) of glaucoma or ocular hypertension (OHT) patients used one antiglaucoma drop and 65\% (132/202) patients needed more than one antiglaucoma drops to control their IOP (Sun X et al, unpublished data, 2007). This crosssectional survey was carried out in 2007 in nine major hospitals in Beijing and Shanghai, which are the most developed cities in the People's Republic of China, and the results gave us an impression that most Chinese patients needed more than one medication to control their IOPs. With the increasing usage of prostaglandin analogs (PGAs) and PGA-timolol fixed combinations, the number of antiglaucoma eye drops used in Chinese glaucoma patients will change and need further study.

The Chinese Glaucoma Society consensus (2014 version) state that glaucoma treatment should focus on lowering IOP to an individualized target to slow disease progression and thus ensure that visual impairment does not occur during the patient's lifetime. ${ }^{17}$.Among the various treatment options currently available, the Chinese Glaucoma Society guidelines recommended PGAs as the first-line treatment because they are administrated once daily and have a higher IOP-lowering efficacy and lower frequency of systemic side effects compared with other antiglaucoma drops. ${ }^{17}$
There is more variation in the daily cost of glaucoma medications in the People's Republic of China compared with that in developed countries. ${ }^{18,19}$ In the People's Republic of China, the cost of a bottle of antiglaucoma eye drops ranges from 0.69 USD (0.5\% timolol; Wuhan Wujin Drug Company, Wuhan, Hubei Province, People's Republic of China) to 40.07 USD (0.005\% latanoprost $/ 0.5 \%$ timolol fixed combination [LTFC]; Xalacom, Pfizer, New York, NY, USA). Although the Chinese Glaucoma Society recommends PGAs as the first-line treatment for POAG, the relatively high price of PGAs has affected their market share in the People's Republic of China, particularly in less-developed areas in the People's Republic of China. Surveys on the Chinese glaucoma medication market performed in 2013 (IMS, China Hospital Audit, unpublished data, 2014 quarter 2) showed that in terms of number, beta-blockers accounted for $44 \%$ of all glaucoma medications, whereas PGAs accounted for only $14 \%$. However, in terms of annual growth, PGAs increased by $29 \%$ compared with $10 \%$ for beta-blockers. These findings suggest that the PGAs are increasingly accepted as the firstchoice treatment by Chinese ophthalmologists and glaucoma patients. According to the surveys conducted by Livingston Market Consultants in 2012 (Allergen, unpublished data, 2012), Chinese ophthalmologists in more developed cities have higher recognition of PGAs than do those in less developed cities. A total of $31 \%$ of physicians in more developed cities preferred PGAs as the first-choice glaucoma medicine compared with $13 \%$ in less developed cities. These differences accounted for the variation in glaucoma treatments across the People's Republic of China.

In conclusion, the population of glaucoma patients in the People's Republic of China is large, and the early diagnosis of POAG in the People's Republic of China remains challenging. Visual impairment in Chinese glaucoma patients is serious, with most patients requiring more than one antiglaucoma eye drop to control their IOPs. Although the GCS recommends PGAs as the first-line treatment, there are large differences in glaucoma treatment patterns across the People's Republic of China.

\section{Overview of PGA-timolol combination therapies in the People's Republic of China and the rationale for combination}

Three types of PGAs are currently available and widely used in the People's Republic of China: 0.03\% bimatoprost (Lumigan $^{\circledR}$; Allergan, Irvine, CA, USA), $0.005 \%$ 
latanoprost (Xalatan ${ }^{\circledR}$; Pfizer), and $0.004 \%$ travoprost (Travatan $^{\circledR}$; Alcon, Fort Worth, TX, USA). The latter two are prodrug esters that are converted into biologically active acids by corneal enzymes and then bind to the prostaglandin $\mathrm{F}_{2 \alpha}$ receptor. Bimatoprost is viewed as a prostamide and might have a slightly different mode of action than the other two agents. ${ }^{20}$ The IOP-lowing effect of bimatoprost is to improve aqueous humor drainage, primarily through the uveoscleral outflow pathway ${ }^{21}$ and partly through the trabecular outflow pathway. ${ }^{22}$

Many patients are unable to achieve their target IOP using monotherapy alone, even with PGAs, ${ }^{14,23}$ and our study (Sun X et al, unpublished data, 2007), suggested 65\% Chinese glaucoma patients need additional medications. Therefore, it is recommended that agents that decrease IOP via different pathways should be combined, one improving aqueous humor outflow and another reducing the production of aqueous humor. Timolol, as a beta-blocker, is the oldest eye drop for reducing the production of aqueous humor and is widely used around the world, while PGAs, as a new type of improved aqueous outflow agent, are also used in more and more countries and regions. When multiple medications are required, fixed combinations should be preferable than two or more separate instillations of agents and have several advantages over the same medications used concomitantly, including convenience, a simpler regimen, better quality of life, avoidance of washout, and decreased exposure to preservatives. ${ }^{24-26}$

Today, there are two PGA-timolol fixed combinations available in the People's Republic of China, including LTFC, launched in the People's Republic of China mainland on March 2009, and a bimatoprost-timolol fixed combination (BTFC) (Ganfort ${ }^{\circledR}$; Allergan) launched in the People's Republic of China mainland on June 2014.

BTFC, a fixed combination of $0.03 \%$ bimatoprost and $0.5 \%$ timolol, was approved in May 2006 by the European Medicines Agency for IOP reduction in patients with openangle glaucoma or OHT. At present, its use and marketing has been approved in more than 30 countries and regions worldwide.

\section{Efficacy studies of bimatoprost and BTFC, including comparative studies \\ Efficacy of bimatoprost}

Several studies, conducted in different countries, have assessed the efficacy of PGA monotherapies on POAG and OHT. In 2005, Holmstrom et al conducted a meta-analysis reviewing the efficacy of three PGAs as the monotherapy and showed that the mean IOP reduction was $26.7 \%, 28.7 \%$, and $30.3 \%$ for latanoprost, travoprost, and bimatoprost, respectively, compared with $22.2 \%$ for timolol. In terms of the proportion of patients that achieved a target IOP, bimatoprost appeared to be the most efficacious agent for any target IOP between 13 and $20 \mathrm{mmHg}$, although the travoprost studies were too few to permit meaningful comparisons. ${ }^{27}$

To study the efficacy of bimatoprost in Chinese patients, we conducted a prospective, open-label, multicenter clinical study in the People's Republic of China. A total 263 Chinese patients with POAG and OHT who needed initial or additional IOP-lowering were recruited in this study and were treated with bimatoprost $0.03 \%$ once daily in the evening. IOP was measured between 8:00 am and 10:00 am before treatment and after 3 months of treatment. The data revealed that bimatoprost achieved a similar IOP reduction in Chinese patients to those from other countries, as shown in Table 1. Treatment-naïve patients achieved a reduction in IOP of $8.0 \pm 3.7 \mathrm{mmHg}(32 \%) 3$ months after commencing bimatoprost monotherapy. In patients who had previously received various therapy regimens, an additional IOP reduction, ranging from $1.9 \pm 2.8 \mathrm{mmHg}(9.5 \%)$ to $6.4 \pm 6.1 \mathrm{mmHg}(24.8 \%)$, was achieved after switching to bimatoprost monotherapy or bimatoprost combination therapy. ${ }^{28}$

A few clinical studies published in Chinese journals have compared the efficacy of the three PGAs available in the People's Republic of China and found no significant difference in IOP reduction among these agents in Chinese patients. In 2005, Jin et al reported a single-center, randomized, investigatormasked, parallel-group clinical trial. A total of 56 patients with

Table I Mean IOP change from baseline, by bimatoprost therapy, in Chinese patients at the 3-month visit

\begin{tabular}{llllll}
\hline & Prior therapy & N & Baseline IOP $\mathbf{( m m H g})$ & IOP reduction $(\mathbf{m m H g})$ & \% reduction \\
\hline Bima $\mathrm{mt}$ & None & 89 & $24.6 \pm 4.4$ & $8.0 \pm 3.7^{* * * *}$ & $32.0 \pm \mathrm{II} .8$ \\
& PGA $\mathrm{mt}$ & 33 & $18.6 \pm 3.4$ & $1.9 \pm 2.8^{* * * *}$ & $9.5 \pm 13.2$ \\
& Non-PGA $\mathrm{mt}$ & 67 & $19.8 \pm 4.0$ & $4.1 \pm 3.5^{* * * *}$ & $18.9 \pm 16.1$ \\
\multirow{3}{*}{ Bima comb } & PGA comb & 18 & $21.4 \pm 5.3$ & $5.3 \pm 5.1^{* * * *}$ & $21.7 \pm 19.5$ \\
& Non-PGA comb & 33 & $23.6 \pm 5.7$ & $6.4 \pm 6.1^{* * * *}$ & $24.8 \pm 20.2$ \\
\hline
\end{tabular}

Notes: ${ }^{* * *} \mathrm{P}<0.00 \mathrm{I}$ compared with baseline IOP in this group, using paired-sample $t$-test or Wilcoxon's signed rank test. Data are presented as mean \pm SD. Abbreviations: Bima, bimatoprost; comb, combination; IOP, intraocular pressure; mt, monotherapy; PGA, prostaglandin analog; SD, standard deviation. 
POAG or OHT received bimatoprost or latanoprost once daily in the evening. IOPs were measured at 8:30 am, 11:30 am, 2:00 pm, and 4:30 pm, before and after 6 weeks of treatment. After 6 weeks, the daily average IOP reduction was $6.95 \pm 3.24 \mathrm{mmHg}$ $(29.9 \%)$ in the bimatoprost group, while the IOP reduction was $8.18 \pm 3.89 \mathrm{mmHg}(34.3 \%)$ in the latanoprost group. The greatest IOP reductions occurred at 8:30 am in both groups. There was no statistically significant difference between the two groups. ${ }^{29}$ In 2006, Kong et al reported a single-center, randomized, investigator-masked, parallel-group clinical trial in which 102 POAG or OHT patients received one of three PGAs including bimatoprost, latanoprost and travoprost once daily at 8:00 pm IOPs were measured at four time points (8:30 am, 11:00 am, 1:30 pm, and 4:00 pm). The greatest IOP reductions occurred at 8:30 am in all three groups. After 4 weeks, the IOP at 8:30 am decreased from $24.57 \pm 3.68 \mathrm{mmHg}$ to $15.29 \pm 2.67 \mathrm{mmHg}$, a reduction of $37.8 \%$, in the latanoprost group, while the IOP decreased from $24.54 \pm 2.95 \mathrm{mmHg}$ to $16.29 \pm 3.11 \mathrm{mmHg}$, a reduction of $33.6 \%$, in the travoprost group, and the IOP decreased from $25.41 \pm 3.63 \mathrm{mmHg}$ to $16.00 \pm 4.45 \mathrm{mmHg}$, a reduction of $37 \%$, in bimatoprost group. They found no statistically significant difference in effectiveness among the three PGA monotherapies. ${ }^{30}$ In 2011, Huang et al reported a case-controlled observational clinical study. A total of 63 POAG patients enrolled in the study and their 24-hour IOPs (every 2 hours) were measured, before and 4 weeks after PGA monotherapy. The daily average IOP in the latanoprost group decreased from $18.9 \pm 2.1 \mathrm{mmHg}$ to $15.3 \pm 2.7 \mathrm{mmHg}$, and the extent of the decrease was $19 \%$. The IOP in travoprost group decreased from $18.6 \pm 1.9 \mathrm{mmHg}$ to $15.3 \pm 2.1 \mathrm{mmHg}$, with a decrease of $19.4 \%$. The IOP in the bimatoprost group decreased from $18.6 \pm 1.9 \mathrm{mmHg}$ to $14.9 \pm 1.9 \mathrm{mmHg}$, with a decrease of $19.9 \%$. The IOP reductions in the three groups had no significant difference. ${ }^{31}$ The low decreases of IOP in this study might have been due to IOP baseline levels before treatment that were lower than in other studies. The circadian variations in IOP in the three groups did not differ significantly.

In summary, the three PGAs cause similar IOP reductions in Chinese POAG or OHT patients. However, all those comparative studies were single-center studies, and the cases were limited and the observation done for a short time. The long-term efficacy of the three PGAs in Chinese patients needs further studies in the future.

\section{Efficacy of BTFC}

A multicenter, observational, noncontrolled, open-label study throughout Europe that enrolled 5,556 patients showed that
BTFC lowered the mean IOP from baseline by $5.4 \mathrm{mmHg}$ over the 12-week study period. In patients with no previous treatment $(\mathrm{n}=311)$, BTFC reduced IOP by $9.1 \mathrm{mmHg}$, corresponding to a reduction from baseline of $36.4 \%$. In patients that had received prior therapy of a PGA, a beta-blocker, or another fixed combination, BTFC reduced IOP by a further $24.5 \%, 25.9 \%$, and $21.4 \%$, respectively. In addition, BTFC achieved long-term IOP-lowing efficacy. ${ }^{32,33}$

Several clinical studies conducted in European countries have reported the superior efficacy of BTFC compared with bimatoprost monotherapy ${ }^{25,33-35}$ or latanoprost monotherapy. ${ }^{32,36}$ There has been no comparative study conducted in the People's Republic of China on the efficacy of BTFCs against PGA monotherapies to date.

To assess the efficacy of BTFC in Chinese patients, we carried out a multicenter, randomized, double-masked, parallel controlled study. Patients with POAG or OHT who were insufficiently responsive to monotherapy using either topical betablockers or PGAs were randomized into one of two treatment groups, in a 1:1 ratio, at eleven Chinese ophthalmic centers. The BTFC group received one drop of a BTFC (fixed combination of $0.03 \%$ bimatoprost and $0.5 \%$ timolol), followed by one drop of vehicle, for masking, once daily at 7:00 pm, and the unfixed-combination group received one drop of $0.03 \%$ bimatoprost followed by one drop of $0.5 \%$ timolol (Allergan) once daily at 7:00 pm. The results are shown in Table 2 . The intent-to-treat (ITT) population included all randomized patients and was used to analyze patient demographics and treatment efficacy. The per-protocol population was the subset of the ITT population with no major protocol deviations. In the ITT population, $93.4 \%$ of patients $(113 / 121)$ in the BTFC group completed the study compared with $91.2 \%$ (104/114) in the unfixed-combination group. In the ITT population, after 4 weeks of treatment, the mean change in mean IOP ( \pm standard deviation) from baseline was $-9.38 \pm 4.66 \mathrm{mmHg}$ in the BTFC group compared with $-8.93 \pm 4.25 \mathrm{mmHg}$ in the unfixed-combination group $(P<0.01)$. The difference in the change from baseline of mean IOP between the two treatment groups (BTFC minus unfixed combination) was $-0.556 \mathrm{mmHg}$ $(P=0.330) .{ }^{15}$ These results indicate that the administration of BTFC to Chinese POAG or OHT patients is not inferior to concurrent dosing using the individual components.

The efficacies of three PGA-timolol combinations have been compared in previous studies conducted in European countries. The results of several prospective, randomized studies supported a significantly higher IOPlowering effect with BTFC compared with LTFC. Centofanti et al reported a prospective, multicenter, investigator-masked 
Table 2 The comparison of efficacy of BTFC and unfixed combinations in Chinese patients

\begin{tabular}{|c|c|c|c|c|}
\hline \multirow[t]{2}{*}{ Visit time } & \multicolumn{2}{|l|}{ ITT } & \multicolumn{2}{|l|}{ PP } \\
\hline & BTFC $(n=121)$ & $\begin{array}{l}\text { Unfixed combo } \\
(n=|| 4)\end{array}$ & BTFC $(n=106)$ & $\begin{array}{l}\text { Unfixed combo } \\
(n=101)\end{array}$ \\
\hline \multicolumn{5}{|l|}{ Baseline } \\
\hline IOP (mmHg) & $25.20 \pm 3.06$ & $24.87 \pm 3.88$ & $25.16 \pm 3.0$ & $24.63 \pm 2.93$ \\
\hline$P$-value between group & $>0.05$ & & $>0.05$ & \\
\hline IOP $(\mathrm{mmHg})$ & $|5.83 \pm 4.2|$ & $|5.95 \pm 5.5|$ & $15.18 \pm 3.40$ & $14.85 \pm 3.36$ \\
\hline IOP change $(\mathrm{mmHg})$ & $\begin{array}{l}-9.38 \pm 4.66 \\
* *\end{array}$ & $\begin{array}{l}-8.93 \pm 4.25 \\
* *\end{array}$ & $\begin{array}{l}-9.98 \pm 4.21 \\
* *\end{array}$ & $\begin{array}{l}-9.79 \pm 3.40 \\
* *\end{array}$ \\
\hline \multicolumn{5}{|l|}{ Week 4} \\
\hline$\%$ reduction & 37.2 & 33.7 & 39.67 & 39.75 \\
\hline Between-group difference & $-0.556(-1.68,0.57)$ & & $-0.26 \mid(-1.30,0.78)$ & \\
\hline$(95 \% \mathrm{Cl})(\mathrm{mmHg})$ & $P=0.330$ & & $P=0.621$ & \\
\hline
\end{tabular}

Notes: $* * P<0.01$ compared with baseline IOP in this group, using paired-sample $t$-test.

Abbreviations: \%, IOP reduction percentage; BTFC, bimatoprost-timolol fixed combination; CI, confidence interval; IOP, intraocular pressure; ITT, intent-to-treat population; PP, per-protocol population.

clinical study in Italy. POAG or OHT patients were randomized to receive either BTFC $(n=47)$ or LTFC $(n=35)$ topical therapy once nightly for 12 weeks. The mean IOP reduction was significantly greater in the BTFC group than in the LTFC group $(-21.4 \%$ vs $-13.7 \%)(P<0.001)$. A higher percentage of patients in the BTFC group showed a mean IOP reduction from baseline, $\geq 15 \%$ ( $72.3 \%$ vs $40.0 \%)$ and $\geq 20 \%(61.7 \%$ vs $17.1 \%$ ), compared with patients in the LTFC group. ${ }^{37}$ In a 4-week trial of 36 patients in Spain, BTFC was associated with superior IOP reduction compared with LTFC at all three time points at week $4 .{ }^{38}$ Similarly, in a 12 -week crossover trial of 54 patients in Spain, BTFC was associated with significantly superior IOP-lowering compared with LTFC at six of seven time points at week $12 .{ }^{39}$

Several prospective randomized studies demonstrated that BTFC causes a greater reduction in IOP than does a travoprost-timolol fixed combination (TTFC). Macky performed a hospital-based prospective randomized study in an Egyptian population to compare the efficacy of BTFC and TTFC. The results showed that BTFC elicited a greater significant mean IOP reduction from baseline than did TTFC at each visit $(P<0.001)$. The mean IOP reduction values were 11.34 and $6.42 \mathrm{mmHg}$ at 2 weeks $(P=0.000)$, and 11.17 and $7.89 \mathrm{mmHg}$ at 6 months $(P=0.001)$ for BTFC and TTFC, respectively. ${ }^{40}$ Centofanti et al carried out a randomized, double-masked, crossover trial in an Italian population to compare BTFC with TTFC..$^{41}$ BTFC was more effective overall at lowering IOP. In particular, BTFC caused a significantly greater mean IOP reduction compared with TTFC, at three of five diurnal time points at 3 month. The mean diurnal IOP was $14.7 \mathrm{mmHg}$ after 3 months with BTFC compared with $15.4 \mathrm{mmHg}$ with TTFC.
Rigollet et al reported a randomized, prospective, singleblinded study in Spain, All three combinations (BTFC, TTFC, and LTFC) were effective at lowering IOP, but at 12 months, LTFC and BTFC were more effective than TTFC. ${ }^{42}$

In 2012, Aptel et al conducted a meta-analysis to review the IOP-lowering effects and tolerability of three PGAtimolol fixed combinations. From direct comparisons, IOP reduction was significantly greatest with BTFC, at 9:00 am, 4:00 pm, and over the mean diurnal curve compared with LTFC (mean difference $=0.90-1.48 \mathrm{mmHg}$ ) $(P<0.001)$ and at all time points compared with TTFC (mean difference $=0.66-0.90 \mathrm{mmHg})(P<0.001){ }^{43} \mathrm{In}$ the same year, Cheng et al published another meta-analysis that reviewed the efficacy of six fixed combinations and reported the relative reduction in mean diurnal IOP was $34.9 \%$ for TTFC, $34.3 \%$ for BTFC, and $33.9 \%$ for LTFC. ${ }^{44}$

Most previous studies in non-Chinese showed that BTFC appears to be slightly more efficacious than LTFC or TTFC; however, there have been no comparative studies of PGA-timolol fixed combinations in the People's Republic of China.

\section{Safety and tolerability}

PGAs have distinctive local adverse reactions, including conjunctival hyperemia, eyelash bristling/lengthening, eyelid pigmentation, iris pigmentation, and upper eyelid deepening. No systemic adverse reactions have been linked to PGA eye drop usage. ${ }^{45}$

\section{Adverse events associated with PGAs}

A meta-analyses of several systematic reviews ${ }^{46}$ showed that conjunctival hyperemia occurred significantly less often with 
latanoprost than with travoprost (odds ratio $=0.512$ ) or with bimatoprost (odds ratio $=0.32$ ). In other meta-analyses based on systematic reviews of patient-reported data, conjunctival hyperemia was more likely to occur with bimatoprost than with latanoprost (relative risk $=1.70$ ) or travoprost (relative risk $=1.19){ }^{47}$

In 2011, Inoue et al investigated the frequency of eyelid pigmentation and eyelash bristles after the use of different PGAs in Japan. The study included 250 patients who were diagnosed with POAG, normal-tension glaucoma, or OHT. The patients were administered one of the PGAs in only one eye for more than 3 months and were followed up at the Inoue Eye Hospital from January to June 2011. The data revealed that eyelash lengthening/number increase occurred $54 \%$, $46 \%$, and $26 \%$ more often in the eye treated with bimatoprost, travoprost, and latanoprost, respectively, compared with untreated eyes. The differences between individual drops were not significant. ${ }^{48}$

All of the PGAs had similar effects on eyelid pigmentation. Specifically, eyelid pigmentation changes occurred in $6 \%, 4 \%$, and $6 \%$ of subjects who received bimatoprost, travoprost, and latanoprost respectively. The differences among agents were not significant. ${ }^{48}$

Deepening of the upper eyelid sulcus (DUES) is another adverse effect of PGAs, and the occurrence of DUES was first reported with bimatoprost in 2004. ${ }^{49}$ The incidence of DUES differs among the various PGAs. Prostaglandin F2-alpha can inhibit fat production. ${ }^{50}$ Therefore, it was thought that PGAs reduced orbital adipose tissue mass to cause DUES. In a study by Inoue et al, 250 POAG or OHT patients were treated in one eye with PGAs, and the other eye was left untreated for more than 3 months. Photographs of the face were taken, and DUES was evaluated using a scoring system. ${ }^{51}$ DUES was reported objectively (photograph) and subjectively (questionnaire) in $24.0 \%$ and $12.0 \%, 50.0 \%$ and $24.0 \%, 60.0 \%$ and $40.0 \%$ of the patients in the latanoprost, travoprost, and bimatoprost groups, respectively. It occurred more frequently (objectively and subjectively) in the bimatoprost group compared with the latanoprost group $(P<0.001)$.

\section{Adverse events associated with BTFC}

Several studies in Europe and the United States showed that fixed combinations led to a lower hyperemia risk than did unfixed combinations and their respective PGA monotherapies. ${ }^{25,32,34,37}$ A meta-analysis that reviewed the incidence of hyperemia was significantly less with LTFC and BTFC than with the individual PGAs (relative risk $=0.66$ and 0.61 , respectively; $P=0.05$ and $P<0.001$, respectively). ${ }^{43}$
In a multicenter, randomized, double-masked, parallel controlled study in the People's Republic of China, of 235 POAG patients, 67 (28.5\%) experienced adverse events: 32 patients $(26.5 \%)$ in the BTFC group and 35 patients $(30.7 \%)$ in the unfixed-combination group. Most adverse events were mild or moderate in severity. Adverse events that the investigator considered to be treatment-related occurred in $20.7 \%(25 / 121)$ of patients in the BTFC group and in $23.7 \%(27 / 114)$ of individuals in the unfixed-combination group (Table 3 ). The most frequent treatment-related adverse event in both groups was conjunctival hyperemia: it occurred in $16.5 \%(20 / 121)$ of patients in the BTFC group and $18.4 \%(21 / 114)$ in the concurrent group, but none of these events was rated as severe. The investigator considered eye pain to be treatment-related in $1.7 \%(2 / 121)$ of patients in the BTFC group and 5.3\% (6/114) of subjects in the unfixed-combination group. Numerically, there were fewer treatment-related adverse events in the BTFC group compared with those in the unfixed-combination group. No treatment-related systemic adverse events occurred during the study. In terms of adverse events, in general, there were no clinically meaningful differences between two treatment groups. ${ }^{15}$

A meta-analysis that reviewed the incidence of hyperemia was not significantly less with LTFC than with BTFC (relative risk $=1.32 ; P>0.1) .{ }^{43}$ Tolerability differences between the fixed combinations appear to be slight, probably because the addition of timolol to the PGA component lessens the associated hyperemia.

\section{Advantages of BTFC for Chinese glaucoma patients}

BTFC has been reported to have great efficacy and tolerability in Chinese patients and scores highly for patient-focused perspectives, such as quality of life, adherence, and

Table 3 The comparison of adverse events of BTFC and unfixed combinations in Chinese patients

\begin{tabular}{|c|c|c|}
\hline & BTFC & Unfixed comb \\
\hline & $(n=121)$ & $(n=|| 4)$ \\
\hline Pts with AE (\%) & 32 (26.45\%) & 35 (30.70\%) \\
\hline Pts with treatment-related & $25(20.66 \%)$ & $27(23.68 \%)$ \\
\hline \multicolumn{3}{|l|}{$\mathrm{AE}(\%)$} \\
\hline Conjunctival hyperemia & $20(16.53 \%)$ & 21 (I8.42\%) \\
\hline Eye pain & $2(1.65 \%)$ & $6(5.26 \%)$ \\
\hline AE caused withdraw & 0 & $2(1.75 \%)$ \\
\hline SAE & 0 & $2(1.75 \%)$ \\
\hline
\end{tabular}

Abbreviations: AE, adverse event; BTFC, bimatoprost-timolol fixed combination; comb, combination; Pts, patients; SAE, severe adverse event. 
acceptability. It also has some advantages that improve patient satisfaction.

First, compared with bimatoprost, BTFC reduces IOP more effectively and can help more glaucoma patients achieve their target IOP. Due to the severity of disease in many Chinese patients with glaucoma, most of individuals need more than one medication to control their IOP. The higher efficacy of BTFC will encourage more of those to control their IOP, which will avoid deterioration of the vision field and thus enable preservation of their quality of life.

Second, instillation of multiple IOP-lowering medications introduces the risk of drug washout and decreased the absorption of medications. ${ }^{25}$ By combining two IOP-lowering agents in the same solution and suspension, fixed-combination eye drops eliminate the risk of drug washout of their components. ${ }^{52,53}$ BTFC can achieve a similar reduction in IOP to unfixed combinations and reduce the times of instillation. Therefore, it can avoid the washout of earlier eye drop and can keep a stable, effective concentration of eye drops.

Third, a reduction in the number of drops required will decrease the amount of preservative, such as benzalkonium chloride, that is deposited on the ocular surface. Agents such as these can damage the health of the conjunctiva and cornea, and even lead to dry eye and other ocular surface diseases. ${ }^{54}$ A survey performed in 1999 with 4,107 patients showed that of a range of symptoms that included discomfort upon instillation, and symptoms between instillations, such as burning and stinging, foreign body sensation, dry-eye sensation, tearing, and eyelid itching, were more prevalent for eye drops that contained preservatives compared with preservative-free eye drops $(P<0.001)$. The incidence of ocular signs was higher in patients using eye drops that contained preservatives, and the prevalence of the signs and symptoms increased as the number of drops instilled increased. In addition, a reduction in symptoms and signs was observed when patients changed from preservative-containing to preservative-free eye drops $(P<0.001){ }^{55}$

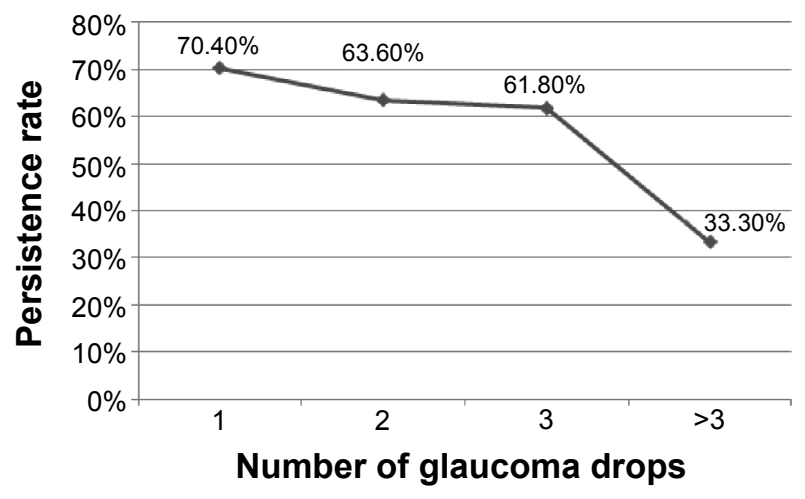

Figure I Change in persistence rates according to number of antiglaucoma drops administrated in a Beijing and Shanghai survey (Sun $X$ et al, unpublished data, 2007).

Fourth, a reduction in the number of eye drops has a beneficial effect on the patients' adherence to the glaucoma treatment and to their persistence with treatment. We carried out a survey on the adherence and persistence rate of glaucoma patients with antiglaucoma eye drops in Shanghai and Beijing. The survey's results showed with the increase of eye drop, from one to more than three, the persistence rate decreased from $70.4 \%$ to $33.3 \%$ (Figure 1) (Sun X et al, unpublished data, 2007).

Fifth, the cost-effectiveness of BTFC in the People's Republic of China is very high. As shown in Table 4, the daily cost of BTFC is cheaper than latanoprost, travoprost, and LTFC. ${ }^{19}$ The daily cost of BTFC is approximately 0.55 USD, which is very close to bimatoprost. Therefore, Chinese patients would be satisfied with the great cost-effectiveness of BTFC.

\section{Conclusion}

The population of glaucoma patients in the People's Republic of China is large. Antiglaucoma fixed combinations have the characteristics of reliable efficacy, low incidence of adverse events, and possibly improved treatment adherence and persistence with treatment, which suggest that they will

Table 4 PGA and PGA-timolol fixed-combination monotherapy bottle contents and costs for the People's Republic of China

\begin{tabular}{llllll}
\hline & BTFC & LTFC & Bima & Latan & Trava \\
\hline Total fill $(\mathrm{mL})$ & $3.08 \pm 0.05$ & $2.65 \pm 0.04$ & $3.08 \pm 0.05$ & $2.65 \pm 0.04$ & $2.55 \pm 0.1$ \\
Drop count & $103 \pm 2.49$ & $90 \pm 7.58$ & $103 \pm 2.49$ & $90 \pm 7.58$ & $94 \pm 2.20$ \\
Vol per drop $(\mathrm{mL})$ & $0.030 \pm 0.000$ & $0.030 \pm 0.003$ & $0.030 \pm 0.000$ & $0.030 \pm 0.003$ & $0.030 \pm 0.001$ \\
Prod price $(\$)$ & 28.3 & 39.8 & 27.7 & 34.9 & 36 \\
Annual cost $(\$)$ & 200 & 323 & 196 & 283 & 277 \\
Daily cost $(\$)$ & 0.549 & 0.885 & 0.536 & 0.774 & 0.76 \\
\hline
\end{tabular}

Notes: Data are presented as mean \pm SD. \$ refers to USD.

Abbreviations: Bima, bimatoprost; BTFC, bimatoprost-timolol fixed combination; Latan, latanoprost; LTFC, latanoprost-timolol fixed combination; PGA, prostaglandin analog; Prod, product; Trava, travoprost; Vol, volume. 
become increasingly popular in the People's Republic of China. As one of the available fixed combinations, BTFC might be a good choice for Chinese glaucoma patients. However, BTFC formally entered the People's Republic of China only in June 2014, and the efficacy of long-term use, the comparative studies with other PGA-timolol fixed combinations, and the effects on Chinese patients' adherence, acceptability, and satisfaction are unknown and will require further study.

\section{Acknowledgment}

Medical writing support was funded by National Natural Science Foundation of China (grant number NSFC81100667).

\section{Disclosure}

Xinghuai Sun is a consultant or speaker for Alcon, Allergan, Pfizer, and Santen. The authors report no other conflicts of interest in this work.

\section{References}

1. Cho HK, Kee C. Population-based glaucoma prevalence studies in Asians. Surv Ophthalmol. 2014;59(4):434-447.

2. Yuan ZL. [Glaucoma clinical trials in China]. Zhonghua Yan Ke Za Zhi. 2012;48(6):485-487. Chinese.

3. Li H, Zhang YY, Liu SC, et al. Prevalence of open-angle glaucoma in southwestern China: the Yongchuan Glaucoma study. J Huazhong Univ Sci Technolog Med Sci. 2014;34(1):137-141.

4. He J, Zou H, Tong X, et al. [Prevalence of primary glaucoma among adults aged 50 years or above population in Huamu community: a cross-sectional survey in Shanghai, 2011]. Zhonghua Yan Ke Za Zhi. 2014;50(5):349-354. Chinese.

5. Liang YB, Friedman DS, Zhou Q, et al; Handan Eye Study Group. Prevalence of primary open angle glaucoma in a rural adult Chinese population: the Handan eye study. Invest Ophthalmol Vis Sci. 2011;52(11): $8250-8257$.

6. Zhong $\mathrm{H}, \mathrm{Li} \mathrm{J}, \mathrm{Li} \mathrm{C}$, et al. The prevalence of glaucoma in adult rural Chinese populations of the Bai nationality in Dali: the Yunnan Minority Eye Study. Invest Ophthalmol Vis Sci. 2012;53(6):3221-3225.

7. Song W, Shan L, Cheng F, et al. Prevalence of glaucoma in a rural northern China adult population: a population-based survey in Kailu county, inner Mongolia. Ophthalmology. 2011;118(10):1982-1988.

8. Yang YF, Yu MB. [Progress of anti-glaucoma fixed combination formulation]. Zhonghua Yan Ke Za Zhi. 2011;47(2):176-180. Chinese.

9. European Glaucoma Society. Terminology and Guidelines for Glaucoma. 3rd ed. Savona: Editrice Dogma; 2008.

10. Lichter PR, Musch DC, Gillespie BW, et al; CIGTS Study Group. Interim clinical outcomes in the Collaborative Initial Glaucoma Treatment Study comparing initial treatment randomized to medications or surgery. Ophthalmology. 2001;108(11):1943-1953.

11. Heijl A, Leske MC, Bengtsson B, Hyman L, Bengtsson B, Hussein M; Early Manifest Glaucoma Trial Group. Reduction of intraocular pressure and glaucoma progression: results from the Early Manifest Glaucoma Trial. Arch Ophthalmol. 2002;120(10):1268-1279.

12. Collaborative Normal-Tension Glaucoma Study Group. Comparison of glaucomatous progression between untreated patients with normaltension glaucoma and patients with therapeutically reduced intraocular pressures. Am J Ophthalmol. 1998;126(4):487-497.
13. VanVeldhuisen PC, Ederer F, Gaasterland DE, et al; The AGIS Investigators. The Advanced Glaucoma Intervention Study (AGIS): 7. The relationship between control of intraocular pressure and visual field deterioration. Am J Ophthalmol. 2000;130(4):429-440.

14. Kass MA, Heuer DK, Higginbotham EJ, et al. The Ocular Hypertension Treatment Study: a randomized trial determines that topical ocular hypotensive medication delays or prevents the onset of primary openangle glaucoma. Arch Ophthalmol. 2002;120(6):701-713; discussion 829-830.

15. Ling Z, Zhang M, Hu Y, et al. Safety and efficacy of bimatoprost/timolol fixed combination in Chinese patients with open-angle glaucoma or ocular hypertension. Chin Med J (Engl). 2014;127(5):905-910.

16. Xu L, Chen JH, Li JJ, et al. [The prevalence and its screening methods of primary open angle glaucoma in defined population-based study of rural and urban in Beijing]. Zhonghua Yan Ke Za Zhi. 2004;40(11):726-732. Chinese.

17. Chinese Glaucoma Society [Glaucoma treatment guidelines]. Zhonghua Yan Ke Za Zhi. 2014;50(5):382-383. Chinese.

18. Fiscella RG, Green A, Patuszynski DH, Wilensky J. Medical therapy cost considerations for glaucoma. Am J Ophthalmol. 2003;136(1):18-25.

19. Gao Y, Wu L, Li A. Daily cost of glaucoma medications in China. J Glaucoma. 2007;16(7):594-597.

20. Liang Y, Woodward DF, Guzman VM, et al. Identification and pharmacological characterization of the prostaglandin FP receptor and FP receptor variant complexes. Br J Pharmacol. 2008;154(5):1079-1093.

21. Toris CB, Gabelt BT, Kaufman PL. Update on the mechanism of action of topical prostaglandins for intraocular pressure reduction. Surv Ophthalmol. 2008;53 Suppl 1:S107-S120.

22. Chen J, Huang H, Zhang S, Chen X, Sun X. Expansion of Schlemm's canal by travoprost in healthy subjects determined by Fourierdomain optical coherence tomography. Invest Ophthalmol Vis Sci. 2013;54(2):1127-1134.

23. Watson PG, Barnett MF, Parker V, Haybittle J. A 7 year prospective comparative study of three topical beta blockers in the management of primary open angle glaucoma. Br J Ophthalmol. 2001;85(8): 962-968.

24. Chrai SS, Makoid MC, Eriksen SP, Robinson JR. Drop size and initial dosing frequency problems of topically applied ophthalmic drugs. J Pharm Sci. 1974;63(3):333-338.

25. Aptel F, Denis P. Balancing efficacy and tolerability of prostaglandin analogues and prostaglandin-timolol fixed combinations in primary open-angle glaucoma. Curr Med Res Opin. 2011;27(10):1949-1958.

26. Khouri AS, Realini T, Fechtner RD. Use of fixed-dose combination drugs for the treatment of glaucoma. Drugs Aging. 2007;24(12): $1007-1016$

27. Holmstrom S, Buchholz P, Walt J, Wickstrøm J, Aagren M. Analytic review of bimatoprost, latanoprost and travoprost in primary open angle glaucoma. Curr Med Res Opin. 2005;21(11):1875-1883.

28. Wang K, Xu L, Yuan Z, et al. Intraocular pressure-lowering efficacy and safety of bimatoprost $0.03 \%$ therapy for primary open-angle glaucoma and ocular hypertension patients in China. BMC Ophthalmol. 2014;14:21.

29. Jin XH, Qian SH, Sun XH. [0.03\% bimatoprost ophthalmic solution with $0.005 \%$ latanoprost eye drops IOP lowering efficacy and safety comparison]. Chinese Journal of Practical Ophthalmology. 2005;23(7): 712-714. Chinese.

30. Kong XM, Sun XH, Meng FR, et al. [A comparison of the ocular hypotensive efficacy of three prostaglandin analogs]. Chinese J Opt and Ophthalmology. 2006;8(4):228-230. Chinese.

31. Huang HL, Sun XH, Xiao M. [Comparison of intraocular pressure reducing effects of three prostaglandin eyedrops in open-angle glaucoma]. Zhonghua Yan Ke Za Zhi. 2011;47(2):109-113. Chinese.

32. Quaranta L, Biagioli E, Riva I, et al. Prostaglandin analogs and timololfixed versus unfixed combinations or monotherapy for open-angle glaucoma: a systematic review and meta-analysis. J Ocul Pharmacol Ther. 2013;29(4):382-389. 
33. Lequeu I, Theuwis K, Abegāo Pinto L, Vandewalle E, Stalmans I. Long term IOP lowering efficacy of bimatoprost/timolol fixed combination: a 12 month prospective study. Bull Soc Belge Ophtalmol. 2013;(322):105-110.

34. Katsanos A, Dastiridou AI, Fanariotis M, Kotoula M, Tsironi EE. Bimatoprost and bimatoprost/timolol fixed combination in patients with open-angle glaucoma and ocular hypertension. J Ocul Pharmacol Ther. 2011;27(1):67-71.

35. Brandt JD, Cantor LB, Katz LJ, Batoosingh AL, Chou C, Bossowska I; Ganfort Investigators Group II. Bimatoprost/timolol fixed combination: a 3-month double-masked, randomized parallel comparison to its individual components in patients with glaucoma or ocular hypertension. J Glaucoma. 2008;17(3):211-216.

36. Gutierrez-Diaz E, Silva Cotta J, Muñoz-Negrete FJ, Gutierrez-Ortiz C, Morgan-Warren RJ, Maltman J. Bimatoprost/timolol fixed combination versus latanoprost in treatment-naïve glaucoma patients at high risk of progression: a pilot study. Clin Ophthalmol. 2014;8:725-732.

37. Centofanti M, Oddone F, Vetrugno M, et al. Efficacy of the fixed combinations of bimatoprost or latanoprost plus timolol in patients uncontrolled with prostaglandin monotherapy: a multicenter, randomized, investigator-masked, clinical study. Eur J Ophthalmol. 2009;19(1):66-71.

38. Martinez A, Sanchez M. A comparison of the safety and intraocular pressure lowering of bimatoprost/timolol fixed combination versus latanoprost/timolol fixed combination in patients with open-angle glaucoma. Curr Med Res Opin. 2007;23(5):1025-1032.

39. Martinez A, Sanchez M. Bimatoprost/timolol fixed combination vs latanoprost/timolol fixed combination in open-angle glaucoma patients. Eye (Lond). 2009;23(4):810-818.

40. Macky TA. Bimatoprost/timolol versus travoprost/timolol fixed combinations in an Egyptian population: a hospital-based prospective randomized study. J Glaucoma. 2014;23(8):561-566.

41. Centofanti M, Oddone F, Gandolfi S, et al. Comparison of Travoprost and Bimatoprost plus timolol fixed combinations in open-angle glaucoma patients previously treated with latanoprost plus timolol fixed combination. Am J Ophthalmol. 2010;150(4):575-580.

42. Rigollet JP, Ondategui JA, Pasto A, Lop L. Randomized trial comparing three fixed combinations of prostaglandins/prostamide with timolol maleate. Clin Ophthalmol. 2011;5:187-191.

43. Aptel F, Cucherat M, Denis P. Efficacy and tolerability of prostaglandintimolol fixed combinations: a meta-analysis of randomized clinical trials. Eur J Ophthalmol. 2012;22(1):5-18.
44. Cheng JW, Cheng SW, Gao LD, Lu GC, Wei RL. Intraocular pressurelowering effects of commonly used fixed-combination drugs with timolol: a systematic review and meta-analysis. PLoS One. 2012;7(9): e45079.

45. Holló G. The side effects of the prostaglandin analogues. Expert Opin Drug Saf. 2007;6(1):45-52.

46. Honrubia F, García-Sánchez J, Polo V, de la Casa JM, Soto J. Conjunctival hyperaemia with the use of latanoprost versus other prostaglandin analogues in patients with ocular hypertension or glaucoma: a meta-analysis of randomised clinical trials. Br J Ophthalmol. 2009;93(3):316-321.

47. Aptel F, Cucherat M, Denis P. Efficacy and tolerability of prostaglandin analogs: a meta-analysis of randomized controlled clinical trials. J Glaucoma. 2008;17(8):667-673.

48. Inoue $\mathrm{K}$, Shiokawa $\mathrm{M}$, Higa $\mathrm{R}$, et al. Adverse periocular reactions to five types of prostaglandin analogs. Eye (Lond). 2012;26(11):1465-1472.

49. Peplinski LS, Albiani Smith K. Deepening of lid sulcus from topical bimatoprost therapy. Optom Vis Sci. 2004;81(8):574-577.

50. Park J, Cho HK, Moon JI. Changes to upper eyelid orbital fat from use of topical bimatoprost, travoprost, and latanoprost. Jpn J Ophthalmol. 2011;55(1):22-27.

51. Inoue K, Shiokawa M, Wakakura M, Tomita G. Deepening of the upper eyelid sulcus caused by 5 types of prostaglandin analogs. J Glaucoma. 2013;22(8):626-631.

52. Holló G, Topouzis F, Fechtner RD. Fixed-combination intraocular pressure-lowering therapy for glaucoma and ocular hypertension: advantages in clinical practice. Expert Opin Pharmacother. 2014; 15(12):1737-1747.

53. Martinez A, Sanchez M. Efficacy and safety of bimatoprost/timolol fixed combination in the treatment of glaucoma or ocular hypertension. Expert Opin Pharmacother. 2008;9(1):137-143.

54. Management and Therapy Subcommittee of the International Dry Eye WorkShop. Management and therapy of dry eye disease: report of the Management and Therapy Subcommittee of the International Dry Eye WorkShop (2007). Ocul Surf. 2007;5(2):163-178.

55. Pisella PJ, Pouliquen P, Baudouin C. Prevalence of ocular symptoms and signs with preserved and preservative free glaucoma medication. Br J Ophthalmol. 2002;86(4):418-423.
Drug Design, Development and Therapy

\section{Publish your work in this journal}

Drug Design, Development and Therapy is an international, peerreviewed open-access journal that spans the spectrum of drug design and development through to clinical applications. Clinical outcomes, patient safety, and programs for the development and effective, safe, and sustained use of medicines are a feature of the journal, which

\section{Dovepress}

has also been accepted for indexing on PubMed Central. The manuscript management system is completely online and includes a very quick and fair peer-review system, which is all easy to use. Visit http://www.dovepress.com/testimonials.php to read real quotes from published authors. 